\title{
O MOVIMENTO IMIGRATÓRIO PARA O BRASIL E AS GARANTIAS FUNDAMENTAIS DOS REFUGIADOS
}

THE IMMIGRATORY MOVEMENT TO BRAZIL AND THE FUNDAMENTAL GUARANTEES OF

REFUGEES

Andréa das Graças Souza Camacho Gimenez GARCIA ${ }^{1}$

Marina Bonissato FRATTARI ${ }^{2}$

Otávio REZENDE ${ }^{3}$

ISSUE DOI: 10.21207/1983.4225.867

\section{RESUMO}

Nos últimos anos, a discussão referente aos imigrantes e refugiados vem crescendo dado o aumento da entrada de estrangeiros no Brasil. A lei que conferia a regulamentação do imigrante no Brasil (Lei 6.815/80) era duramente criticada por ser protecionista, visando sempre à segurança nacional, deixando os direitos humanos em segundo plano, o que não era bem recepcionado pela constituição e a tratados internacionais. No ano de 2017 foi aprovada e sancionada a Lei 13.445/2017, que possui um olhar mais humanitário sob o estrangeiro. Posto isto, o trabalho possui como objetivo analisar o

\footnotetext{
${ }^{1}$ Docente concursada da Universidade do Estado de Minas Gerais, Unidade Frutal (UEMG Frutal), com as disciplinas Direito Empresarial, Terceiro Setor, Monografia e Metodologia da Pesquisa Científica. Doutora e Mestre pela Universidade Estadual Paulista Júlio de Mesquita Filho - Faculdade de Ciências Humanas e Sociais (UNESP-Franca). Graduada pela Faculdade de Direito de Franca (1996). Advogada nas áreas cível e Direito Administrativo. Currículo Lattes: http://lattes.cnpq.br/1584234885647195. Contato: andrea.garcia@uemg.br.

${ }^{2}$ Pós-Graduanda em Direito Processual Civil Empresarial. Bacharel em Direito pela Universidade do Estado de Minas Gerais (UEMG), Frutal/MG. Currículo Lattes: http://lattes.cnpq.br/8160577624852379. Contato: marina.b.frattari@hotmail.com.

${ }^{3}$ Advogado. Formado em Direito pela Universidade do Estado de Minas Gerais (UEMG), Frutal/MG. Contato: otavio_rezende@live.com.
} 
movimento migratório para o Brasil, analisando toda a legislação pertinente aos estrangeiros, o acesso a ela, e como são assegurados a esses direitos de ordem fundamental, sejam eles imigrantes ou refugiados. Também, almeja investigar a existência de políticas públicas para inclusão dos refugiados no âmbito da educação, da comunicação e acesso à saúde, constatar se existe discriminação religiosa com os imigrantes muçulmanos e verificar de que maneira acontece o ingresso dos refugiados no mercado de trabalho. Para tanto, a metodologia utilizada no presente trabalho parte da investigação de material doutrinário, artigos científicos e legislações, além de materiais audiovisuais, com o fim de investigar como o fenômeno da imigração é tratado atualmente no Brasil, visando analisar se os direitos humanos de ordem fundamental são assegurados aos estrangeiros e devidamente respeitados pelo nosso Estado, além de buscar identificar o que atraem imigrantes e para o Brasil, sejam os. Sendo assim, concluiu-se esta pesquisa com dados pertinentes sobre o atual movimento imigratório para o Brasil, as consequências sociais e jurídicas do crescente número de refugiados e suas garantias fundamentais no âmbito do ordenamento jurídico brasileiro.

Palavras-chave: Refugiados; Movimento migratório; Garantias jurídicas.

\begin{abstract}
In recent years, the discussion regarding immigrants and refugees has grown due to the increase in the entry of foreigners into Brazil. The law that conferred the regulation of immigrants in Brazil (Law 6.815 / 80) was severely criticized for being protectionist, always aiming at national security, leaving human rights in the background, which was not well received by the constitution and international treaties. In the year 2017, Law 13,445 / 2017 was approved and sanctioned, which has a more humanitarian view under the foreigner. That said, the work aims to analyze the migratory movement to Brazil, analyzing all legislation relevant to foreigners, access to it, and how these fundamental rights are guaranteed, whether they are immigrants or refugees. It also aims to investigate the existence of public policies for the inclusion of refugees in the scope of education, communication and access to health, to see if there is religious discrimination against Muslim immigrants and to see how refugees enter the labor market. Therefore, the methodology used in the present work starts from the investigation of doctrinal material, scientific articles and legislation, in addition to audiovisual materials, in order to investigate how the phenomenon of immigration is currently treated in Brazil, aiming to analyze whether human rights of order fundamental are guaranteed to foreigners and duly respected by our State, in addition to seeking to identify what attracts immigrants and to Brazil, be they. Thus, this research was concluded with pertinent data on the current immigration movement to Brazil, the social and legal consequences of the growing number of refugees and their fundamental guarantees within the scope of the Brazilian legal system.
\end{abstract}

Keywords: Refugees; Migration movement; Legal guarantees.

\title{
INTRODUÇÃO
}

O processo de imigração é o movimento de entrada de pessoas de um país para outro, ocorre muitas vezes por iniciativa própria e com o desejo de permanência. Geralmente estão em busca de melhores condições de vida e de trabalho, podendo ocorrer também por motivos alheios à vontade do imigrante, como no caso do refúgio, em que os indivíduos saem de seu país de origem devido a pressões sociais, econômicas ou políticas, que os obriga buscarem liberdade de expressão em outros países. 
Devido a isso, cresce vertiginosamente o número de imigrantes que entram ilegalmente em território brasileiro e aqui permanecem sem documentação adequada. A situação torna-se preocupante não só por isso, mas porque corriqueiramente os imigrantes instalados em território nacional em situação irregular são vítimas de violações de direitos básicos como liberdade, educação e saúde, muitas vezes submetidos à condição análoga de escravos.

Ocorre, pois, que há tendência de as imigrações no país continuarem aumentando, sobretudo, de populações advindas de países subdesenvolvidos ou com uma precária situação econômica, além de povos de regiões marcadas por grandes conflitos, com destaque para povos da Palestina e mais recentemente, da Síria.

Quanto às condições de vida, muitos dos estrangeiros no Brasil sofrem com as precárias condições de vida que aqui encontram, sobretudo no momento em que chegam, quando ainda não dispõem de emprego, moradia, comida e dinheiro, além de sequer conhecerem o idioma português.

Ainda, não são poucos os casos de trabalhos análogos ao escravo praticados no país, sobretudo com migrantes haitianos na região Norte e aumento do tráfico de pessoas. Assim, com o Brasil tornando-se um novo centro de atração de imigrantes ilegais, consequentemente surge outra problemática: o aumento do número de tráfico de pessoas.

Atualmente os principais esforços do governo brasileiro são no sentido de investigar e punir a prática criminosa desses grupos, que além de cobrarem alto pela "ajuda" na imigração ilegal, cometem vários crimes contra os direitos humanos durante o percurso.

Diante do exposto, este trabalho dirige um olhar significativo, com o devido suporte teórico da base formativa, permitindo assim reflexões e análises sobre o fenômeno a ser estudado, qual seja, o atual movimento imigratório para o Brasil, as consequências sociais e jurídicas do crescente número de refugiados e suas garantias fundamentais no âmbito do ordenamento jurídico brasileiro.

A pesquisa foi desenvolvida por meio do método de pesquisa bibliográfico e documental, na área de atuação dos pesquisadores, qual seja Direitos Humanos.

Quanto à abordagem, o presente estudo é de caráter qualitativo e quantitativo, pois se entende de antemão que houve dados mensurados e, também, análises de caráter subjetivo. O método utilizado foi o indutivo, 
para a obtenção de melhores resultados, analisando os dados coletados, doutrinas pertinentes ao tema e, ainda, análise de pesquisas antropológicas e sociológicas, a respeito da temática proposta.

\section{DA IMIGRAÇÃO NO BRASIL}

A legislação nacional, com o advento do Texto Constitucional de 1988, assegura a todas as pessoas os direitos e garantias essenciais para que possam ter uma vida pautada pelo princípio da dignidade da pessoa humana, sendo tal princípio fundamento da República Federativa do Brasil, conforme estabelece o art. $1^{\circ}$, inciso III o diploma legal apontado acima.

A Carta Maior traz ainda em diversos outros pontos direitos que são assegurados tanto aos estrangeiros, como também aos nacionais, dentre eles vale ressaltar a igualdade, consubstanciado no art. $5^{\circ}$, que dispõe: "todos são iguais perante a lei, sem distinção de qualquer natureza, garantindo-se aos brasileiros e aos estrangeiros residentes no País a inviolabilidade do direito à vida, à liberdade, à igualdade, à segurança e à propriedade (...) ${ }^{4}$ '.

Como extrai do texto legislativo citado, o cidadão brasileiro e os estrangeiros em trânsito no território nacional constituem-se destinatários finais de direitos e garantias fundamentais, sobre o tema ensina Alexandre de Moraes:

$\mathrm{O}$ art. $5^{\circ}$ da Constituição Federal afirma que todos são iguais perante a lei, sem distinção de qualquer natureza, garantindo-se aos brasileiros e aos estrangeiros residentes no País a inviolabilidade do direito a vida, à liberdade, à igualdade, à segurança e à propriedade. Observe-se, porém, que a expressão residentes no Brasil deve ser interpretada no sentido de que a Carta Federal só pode assegurar a validade e gozo dos direitos fundamentais dentro do território brasileiro $[\ldots] .^{5}$

Desta maneira, percebe-se que todas as pessoas são destinatários de direitos humanos fundamentais, de modo que se pode encontrar em

\footnotetext{
4 BRASIL. Constituição da República Federativa do Brasil. Disponível em: http://www.planalto.gov.br/ccivil 03/Constituicao/ConstituicaoCompilado.htm. Acesso em 13.Dez.2017

${ }^{5}$ MORAES, Alexandre de. Direitos humanos fundamentais: teoria geral, comentário aos arts. $1^{\text {a }}$ ao $5^{\circ}$ da Constituição da República Federativa do Brasil, doutrina e jurisprudência. $9^{a}$ ed. São Paulo, Atlas. 2011. p. 75.
} 
vários pontos da Lei Maior, e não só no art. $5^{\circ}$, garantias fundamentais, como no art. 3, inciso IV, art. $4^{\circ}$ e art. 21.

Além da Constituição Federal, outras leis infraconstitucionais também abordam matérias pertinentes aos estrangeiros, como, por exemplo, a Lei 13.445 de 24 de maio de 2017 (Lei de Migração), que é considerada um grande avanço naquilo que tange a imigração, pois referida legislação aborda aquelas originários de outros países como ser humano, deixando de lado a visão protecionista que o da legislação anterior.

Concomitantemente à abordagem dos aspectos da Lei de Migração, é importante ressaltar o Estatuto do Estrangeiro (Lei 6.815, de 19 de agosto de 1980). O referido diploma não vigora mais no Brasil, mas a necessidade de abordá-lo brevemente no presente trabalho é latente, uma vez que assim pode-se comparar a evolução da legislação nacional, bem como o passo dado pelo Brasil em matéria de Direitos Humanos.

A Lei 6.815/80 disciplinava a entrada e saída de pessoas provenientes de outros países no território nacional, com seus aspectos voltados primeiramente para a segurança nacional, assim como para a organização institucional. Referido diploma, logo no em seu art. $2^{\circ}$ já mostrava o espírito da norma, que assim dizia:

\section{Art. $2^{\circ} \mathrm{Na}$ aplicação desta Lei atender-se-á precipuamente à segurança nacional, à organização institucional, aos interesses políticos, sócio-econômicos e culturais do Brasil, bem assim à defesa do trabalhador nacional ${ }^{6}$.}

Destarte, podemos extrair da norma acima o seu caráter voltado para a segurança nacional, bem como para outros aspectos importantes, e que naquela época tinha-se a ideia de que poderiam ser influenciados pelos estrangeiros, como por exemplo, o trabalho. Era evidente o receio tido pelos governantes daquela época do ingresso de nacionais de outros países no território nacional.

Vale lembrar que no tempo da edição do Estatuto do Estrangeiro, o Brasil vivia sob o controle dos militares, e como é cediço, o regime militar é marcado pelo protecionismo exacerbado, de modo a colocar o Estado à frente de direitos fundamentais.

Superada a legislação anterior, passa-se a análise da legislação recente, a Lei 13.445/2017 (Lei de Migração), que entrou em vigor em

\footnotetext{
6 BRASIL. Lei 6.815, de 19 de agosto de 1980. Disponível em: <http://www.planalto.gov.br/ccivil_03/leis/L6815.htm>. Acesso em: 13.Dez.2017
} 
novembro de 2017. A Lei de Migração constitui uma evolução do Brasil em relação aos Direitos Humanos, e principalmente naquilo tangente ao estrangeiro.

O novo diploma encara aquele que vem de outros países, ou que são apátridas, de modo a assegurar condições mínimas no território nacional para que eles possam ter uma vida digna, bem como preceitua o Texto Maior. A legislação mais nova abandona o protecionismo e coloca o ser humano em primeiro lugar.

A Lei 13.445/17 visa regular a entrada e saída do país, assim como também dispõe dos direitos e deveres dos nacionais de outros países no território brasileiro, estabelecendo ainda princípios e diretrizes para o desenvolvimento de políticas públicas para o estrangeiro, conforme estabelece $o$ art. $1^{\text {a }}$ da citada norma.

Como mencionado, a Lei de Migração possui suas vertentes voltadas para os Direitos Humanos, posto isto, vale trazer a baila a transcrição de seu $3^{\circ}$ e incisos:

Art. $3^{\circ}$ A política migratória brasileira rege-se pelos seguintes princípios e diretrizes:

I - universalidade, indivisibilidade e interdependência dos direitos humanos;

II - repúdio e prevenção à xenofobia, ao racismo e a quaisquer formas de discriminação;

III - não criminalização da migração;

IV - não discriminação em razão dos critérios ou dos procedimentos pelos quais a pessoa foi admitida em território nacional;

$\mathrm{V}$ - promoção de entrada regular e de regularização documental;

VI - acolhida humanitária;

VII - desenvolvimento econômico, turístico, social, cultural, esportivo, científico e tecnológico do Brasil;

VIII - garantia do direito à reunião familiar;

IX - igualdade de tratamento e de oportunidade ao migrante e a seus familiares;

$\mathrm{X}$ - inclusão social, laboral e produtiva do migrante por meio de políticas públicas;

XI - acesso igualitário e livre do migrante a serviços, programas e benefícios sociais, bens públicos, educação, assistência jurídica integral pública, trabalho, moradia, serviço bancário e seguridade social;

XII - promoção e difusão de direitos, liberdades, garantias e obrigações do migrante;

XIII - diálogo social na formulação, na execução e na avaliação de políticas migratórias e promoção da participação cidadã do migrante; 
XIV - fortalecimento da integração econômica, política, social e cultural dos povos da América Latina, mediante constituição de espaços de cidadania e de livre circulação de pessoas;

XV - cooperação internacional com Estados de origem, de trânsito e de destino de movimentos migratórios, a fim de garantir efetiva proteção aos direitos humanos do migrante;

XVI - integração e desenvolvimento das regiões de fronteira e articulação de políticas públicas regionais capazes de garantir efetividade aos direitos do residente fronteiriço;

XVII - proteção integral e atenção ao superior interesse da criança e do adolescente migrante;

XVIII - observância ao disposto em tratado;

XIX - proteção ao brasileiro no exterior;

$\mathrm{XX}$ - migração e desenvolvimento humano no local de origem, como direitos inalienáveis de todas as pessoas;

XXI - promoção do reconhecimento acadêmico e do exercício profissional no Brasil, nos termos da lei; e

XXII - repúdio a práticas de expulsão ou de deportação coletivas ${ }^{7}$.

$\mathrm{O}$ artigo apontado anteriormente deixa clara a vontade do legislador brasileiro de proteger o ser humano, de modo que o Brasil veio adotar as normas de Direitos Humanos Fundamentais, e assim garante a todos as condições básicas necessárias para a sobrevivência, independentemente de qual nacionalidade seja.

\section{$3 \quad$ DAS POLÍTICAS PÚBLICAS}

Há um aumento no número de refugiados no Brasil, em 2015 o país recebeu 28.670 solicitações de refugiados, representando um aumento significativo de $2.86 \%$ em relação ao ano de 2010. Essas pessoas saem de seus países devido a conflitos instalados em seus territórios, perseguições religiosas também são alguns dos fatores relevantes que fazem com que peçam refúgio no Brasil.

Devida à fragilidade em que se encontra o imigrante é necessário que o país que o receba com políticas públicas que possam reinseri-lo na sociedade e promover condições de vida digna, livre de quais tipos de preconceito ou discriminação.

A Lei 13.445/17, em seu art. $3^{\circ}$, incisos, V, IX, X, XI, XII, XIII e XXI estabelece princípios e diretrizes para o desenvolvimento de

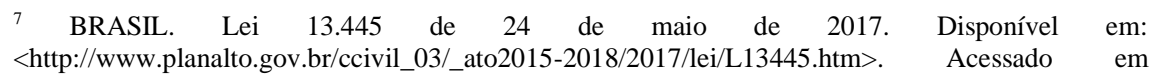
13.Dez.2017. 
políticas públicas para os estrangeiros, dentre as constantes no permissivo legal encontra-se o acesso ao judiciário, a educação pública, inclusão laboral, dentre outras elencadas no referido artigo.

No Brasil, o Comitê Nacional Para Refugiados (CONARE) é responsável por receber e aprovar os pedidos de refúgio, além de ter em seu encargo também a promoção de ações que visam a proteção do refugiado e sua reintegração social.

O Brasil vem adotando algumas medidas com o fim de assegurar o desenvolvimento de políticas públicas para os imigrantes, como a I Conferência Nacional sobre Migração e Refúgio, que aconteceu em 2014, onde reuniam migrantes e estudiosos sobre a temática, além de todas as outras pessoas interessadas na discussão, e a elaboração de propostas para o Plano Nacional de Migração e Refúgio.

Apesar do Brasil se esforçar para desenvolver políticas públicas para os migrantes e refugiados, vale destacar que é imperioso o trabalho de organizações da sociedade civil, juntamente com a ACNUR, que visam promover o tratamento igualitário desses imigrantes, além de promover meios para sua instalação no território brasileiro.

\subsection{PROCESSO IMIGRATÓRIO E A TENTATIVA DE ACOLHIDA HUMANITÁRIA NO BRASIL}

O Brasil está na rota dos imigrantes desde sua colonização, onde portugueses pisaram em terras tupiniquins trazendo seus costumes e habitando permanentemente seus solos. Logo vieram espanhóis, holandeses, franceses e outras nacionalidades europeias para trabalharem no país continental, trazendo consigo várias etnias diferentes, como os bantos africanos. O país, característico por abrigar várias nacionalidades, é uma colcha de retalhos, cuja cultura é formada por características distintas e variáveis.

A imigração no Brasil não cessou e, desde sua colonização, este país mestiço abriga povos das mais variadas etnias. Exemplo disso é um grande número de haitianos vindos ao Brasil nos últimos anos, através da Amazônia, em busca de emprego e melhores condições de vida. Durante a Copa do Mundo de 2014, por exemplo, o mesmo processo ocorreu, destacando-se os imigrantes oriundos de Gana, que se deslocaram para o Brasil em função do torneio, mas não retornaram para o seu país de origem. 
Outros países que se destacaram no envio de imigrantes foram Bangladesh, Senegal, Angola, entre outros. A expansão das imigrações atuais no Brasil vem acompanhada por uma série de fatores, como por exemplo, o aumento da xenofobia: sobretudo para com as populações advindas de países subdesenvolvidos. Para parte da população brasileira, os grupos estrangeiros trazem doenças, "roubam" vagas de empregos e "ameaçam" a identidade cultural do país, entre outros.

Além de ser o principal foco deste fluxo, a cidade de São Paulo é um destino tradicional de imigração de diversas outras nacionalidades. Neste contexto, a Secretaria Municipal de Direitos Humanos e Cidadania (SMDHC), por meio da Coordenação de Políticas para Migrantes, inaugurou em agosto de 2014, o Centro de Referência e Acolhida para Imigrantes da Cidade de São Paulo (CRAI-SP). Pioneira no Brasil, a iniciativa é um compromisso da cidade com os direitos humanos e o direito do imigrante.

Inspirada nos Centros Nacionais de Apoio ao Imigrante (CNAI) de Portugal, o CRAI-SP visa acolher e dar suporte a migrantes em trânsito ou residentes na Cidade, independentemente da nacionalidade, do status migratório ou do amparo legal para a sua estada em território nacional (SÃO PAULO, 2015).

Importante ressalvar, em oportunidade, que existe diferença entre os termos imigrantes e refugiados. Diferentemente de imigrantes, que na maioria das vezes entram em outro país por livre iniciativa e/ou desejo, os refugiados são pessoas que se encontram fora do seu país por motivos de força maior, ou seja, por temor de perseguição por motivos de raça, religião, nacionalidade, opinião política, participação em grupos sociais ou violação generalizada de direitos humanos e que não possam, ou não queiram, voltar para casa.

Os fundamentos da proteção aos refugiados, nos quais se baseiam inúmeras leis e práticas internacionais, são a Convenção da Organização das Nações Unidas - ONU sobre Refugiados de 1951 e seu Protocolo de 1967.

No Brasil, a questão sobre os refugiados é regulada pela Lei ${ }^{\circ}$ 9.474, de 22 de julho de 1997, a qual criou o Comitê Nacional para os Refugiados - CONARE. O CONARE, por sua vez, é um órgão colegiado, vinculado ao Ministério da Justiça, que reúne segmentos representativos da área governamental, da Sociedade Civil e das Nações Unidas (ACNUR) e que tem por finalidade analisar e decidir todos os pedidos de refúgio no 
Brasil. É também o órgão encarregado de formular a política sobre refúgio no Brasil e criar normas que esclareçam os termos da lei de refúgio.

Foi aprovado no Congresso Nacional o Projeto de Lei que institui uma nova Lei de Migração para o Brasil, em substituição ao defasado Estatuto do Estrangeiro (Lei 6.815/1980), forjado ainda no período da ditadura militar.

Trata-se do Projeto de Lei do Senado 288/2013, que foi para tramitação na Câmara dos Deputados como Projeto de Lei 2.516/2015, em regime de prioridade. A proposta da nova Lei de Migração brasileira, que já representa grande avanço na proteção de direitos humanos em relação ao Estatuto do Estrangeiro vigente, ainda pode ser aprimorada a partir do debate democrático no Poder Legislativo, evitando contradições e até mesmo alguns pontos de retrocesso.

O projeto de lei prevê expressamente princípios e garantias, em consonância com as diretrizes de proteção internacional de direitos humanos, que podem servir para nortear políticas públicas e decisões judiciais em favor da proteção dos direitos humanos dos migrantes.

Destacam-se as seguintes previsões: repúdio à xenofobia, ao racismo e à discriminação; não criminalização da imigração; previsão de hipótese de regularização migratória com fundamento em acolhida humanitária; direito de reunião familiar; direitos para fronteiriços; proteção de crianças e adolescentes; igualdade de direitos com brasileiros no acesso a serviços públicos e direitos sociais, entre outros (BRASIL, 2014).

O Centro de Referência é mantido por intermédio de um convênio com o Ministério da Justiça (MJ) e contará com assistência social, jurídica e psicológica especializada, além de curso de língua portuguesa e uma média estimada de 200 atendimentos por mês para imigrantes, refugiados, solicitantes de refúgio, portadores de visto humanitário, retornados e estudantes estrangeiros.

No mesmo espaço funcionará um Centro de Acolhida com 110 vagas noturnas e 80 diurnas, com perspectivas de expansão. O projeto é uma ação da Secretaria Municipal de Direitos Humanos e Cidadania (SMDHC) em parceria com a Secretaria Municipal de Assistência e Desenvolvimento Social (SMADS), com apoio do Ministério do Desenvolvimento Social (MDS) (SÃO PAULO, 2015).

\subsection{INSERÇÃO DO REFUGIADO NO MERCADO DE TRABALHO}


A inserção do refugiado no mercado de trabalho é algo complexo e muitas vezes pautada no preconceito. Desta feita, muitas vezes quando o refugiado consegue algum emprego é comumente discriminado em decorrência de sua origem, ou ainda, conseguem empregos que não necessitam de grande qualificação profissional, como, por exemplo, de peões em obras.

Frequentemente, para a obtenção de emprego no solo brasileiro os refugiados necessitam da ajuda de Organizações Não Governamentais (ONG's), que os auxiliam na busca do labor, além de ajuda-los na aprendizagem da nova língua. Contudo, mesmo aqueles refugiados que possuem instrução, conseguem empregos que exigem pouca ou nenhuma qualificação.

\subsection{ASSISTÊNCIA SOCIAL E SAÚDE}

Segundo Miles e Carlet (2006), individual ou coletivamente, a mobilidade humana contemporânea é motivada por diferentes circunstâncias e fatores ligados, de algum modo, a uma sociedade complexa, mais marcada pelos desequilíbrios sócio-econômicos, pela violência e intolerância do que pelo respeito à igualdade e à dignidade humana.

\footnotetext{
Os refugiados, vulneráveis entre os vulneráveis, são a crua expressão das desordens e desequilíbrios mundiais. Não querem deslocar-se, são compelidos ou constrangidos a tal. São homens, mulheres e crianças obrigados a deixar sua pátria por fundado temor de perseguição seja por motivos de raça, religião, nacionalidade ou opinião, seja pela própria violação de direitos e falta de proteção do seu Estado (MILES e CARLET, 2006).
}

Os imigrantes e os refugiados buscam se afastar da pobreza, procurando em outros países melhores condições de emprego e qualidade de vida, fugir das perseguições políticas e ideológicas, do preconceito, da intolerância, muitas vezes de guerras e conflitos que ameaçam suas garantias fundamentais, como a própria vida. Também, buscam a liberdade de expressão, de ir e vir e o direito baluarte da dignidade.

Para Miles e Carlet (2006), esta busca deve despertar os governos, a população, as entidades e os indivíduos para uma revisão de 
valores e promoção de iniciativas concretas a favor da vida e do respeito ao ser humano.

É nesta ótica que se ressalva a importância de políticas públicas e benefícios sociais que atendam às necessidades de imigrantes e refugiados. Acontece que essas pessoas que adentram no país para buscarem melhor qualidade de vida ou mesmo a garantia de seus direitos fundamentais, são marginalizadas pela população nacional devido a conceitos protecionistas ou até mesmo preconceituosos.

Sendo assim, é de suma importância que o governo, entidades governamentais ou não governamentais e os próprios cidadãos nacionais tomem consciência da importância de se praticar ações que diminuam a diferença social dessas pessoas que adentram em nosso território, uma vez ser preciso atenuar as dificuldades enfrentadas por aqueles que muitas vezes chegam aqui sem saberem nem o idioma local, sendo ainda uma ação de solidariedade e justiça.

Por isso que políticas públicas voltadas à assistência e integração dos refugiados são imprescindíveis para assegurar-lhes os direitos econômicos, sociais e culturais, em especial o direito ao trabalho, à saúde e à educação.

A Constituição Federal e o Estatuto dos Refugiados, o qual é representado pela Lei 9.474/97, oferecem suporte legal e constitucional à implementação de políticas públicas e benefícios sociais que garantam a efetivação destes direitos.

Os artigos 43 e 44 da Lei 9.474/97 destacam a necessidade de tratamento a quem de fora vier se refugiar no Brasil: simplificação das exigências na apresentação de documentos do país de origem; facilitação no reconhecimento de certificados e diplomas e flexibilidade para o ingresso em instituições acadêmicas.

Por sua vez, o art. 203 da Constituição Brasileira de 1988, garante a prestação de assistência social "a quem dela precisar", tendo como um de seus objetivos a promoção da integração ao mercado de trabalho (inciso III).

Em consonância a isto, Miles e Carlet (2006), são claras ao afirmar que:

Pese à importância destas disposições, essencialmente no que se refere à implementação de políticas públicas para refugiados ou o acesso destes às já existentes, o Poder Público permanece, ainda, bastante distante. Facilmente delega à sociedade civil a efetivação 
da tarefa, abstendo-se de trazer para si o cumprimento desta responsabilidade.

A passos lentos, algumas iniciativas vêm se solidificando na da educação básica e superior, no trabalho, saúde e integração. Essas ações ocorrem em parceria entre governo e diferentes setores da sociedade para que, principalmente os refugiados insiram-se nos espaços sociais e laborais, atenuando, assim, as lacunas de sua exploração e discriminação.

Exemplo disso são as propostas voltadas para a saúde. Muitas vezes o refugiado se encontra doente e no país de acolhida não dispõe da possibilidade de tratamento médico adequado, ou devido a problemas de saúde se encontra em situação de dependência de um sistema de proteção social ou da presença de familiares.

Para isso, programas já foram criados, como o primeiro Centro de Referência para a Saúde dos Refugiados, instalado no Hospital dos Servidores do Estado do Rio de Janeiro, com o objetivo de capacitar profissionais do Sistema Único de Saúde (SUS) para atender tais indivíduos.

Atualmente existem outros programas que dão assistência aos imigrantes e refugiados, sendo eles instituídos por universidades públicas e privadas, ONGs ou grupos de assistência. Contudo, não atendem à real demanda, o que leva a ser frequente os relatos de imigrantes sobre barreiras enfrentadas diariamente quanto acesso à rede de saúde, como discriminação, desinformação, desrespeito à diversidade cultural e despreparo dos profissionais no atendimento.

Tudo isso faz com que o questionamento a respeito do princípio de universalidade exista. É necessário pensar propostas de enfrentamento, que possam garantir acesso de todos e todas aos direitos sociais previdência, assistência social e, especialmente, o direito à saúde.

Eleva-se que esses programas deveriam centrar no fato de que os refugiados chegam ao país com dificuldade de comunicação, traumas psicológicos em razão das guerras e da violência que sofreram. São casos que requerem maior sensibilidade na acolhida, atenção às condições emocionais e psíquicas, e consideração por parte dos profissionais da saúde.

Os espaços que devem ser melhores preenchidos e algumas ações mais abrangentes são: garantir atendimento global à saúde dos refugiados nos serviços de saúde pública, inclusive de saúde psicossocial; elaborar um Programa de Saúde para atendimento à população refugiada e identificação 
de hospitais de referência; criar junto às universidades públicas a possibilidade de atendimento odontológico; intervir na formalização de acordos junto às Secretarias de Saúde (Estadual e/ou Municipal) para políticas de saúde de atendimento local aos refugiados.

Outro exemplo são os programas de apoio e serviços sociais que são ofertados aos estrangeiros que vêm ao país. No Brasil, os refugiados e solicitantes de refúgio são contemplados pelas mesmas leis e programas sociais que os aqui nascidos. Portando apenas um CPF (Cadastro de Pessoa Física), que é concedido mesmo antes do status de refugiado ter sido aprovado, esse perfil de imigrante pode realizar o Cadastro Único nas secretarias municipais de assistência social ou nos Centros de Referência de Assistência Social (CRAS) e, por meio dele, ter acesso aos programas sociais existentes, como o Bolsa-Família.

O Bolsa-Família, de acordo com dados divulgados pela BBC Brasil, beneficia cerca de 400 imigrantes sírios que vieram para o Brasil, de acordo com o Ministério do Desenvolvimento Social e Combate à Fome. A pasta não informou o valor específico recebido pelos sírios - mas o benefício médio do programa é de $\mathrm{R} \$ 167$ mensais por família.

Também, o governo brasileiro, diferentemente de outros países, não tem um programa específico apenas para refugiados que ofereça diretamente ajuda financeira a eles, desta forma, o Bolsa-Família funciona como um programa subsidiário.

Constata-se que apenas nos últimos anos é que a o serviço social vem verificando a necessidade de intervenção especificamente com essa população, sendo ela a de refugiados. Percebeu-se a vulnerabilidade social. Talvez isso ocorra pelo contingente populacional que tem se deslocado e pela maneira como fazem esse deslocamento e se estabelecem no Brasil.

Ainda que localmente, o refugiado e imigrante legalizados tenham acesso aos programas sociais e à saúde gratuita, que segundo a Constituição brasileira é universal, há a necessidade de um aprimoramento dos aparatos legais voltados especificamente à esta população.

No campo da Previdência Social, a exemplo, não existem acordos internacionais com muitos países de origem para que os registros de trabalhos anteriores de imigrantes sejam considerados válidos no cálculo da aposentadoria. A falta de capacitação de alguns dos profissionais que lidam com pessoas em situação de refúgio também é um complicador na sua reintegração e a impossibilidade de se comunicar em outros idiomas 
dificulta a comunicação, o que pode gerar situações em que eles se sintam constrangidos ou discriminados.

Outra questão que dificulta o atendimento do refugiado é a falta de conhecimento sobre seus próprios direitos estando no Brasil, o que gera equivocadamente uma postura de inferioridade, a qual se aproveitam alguns profissionais e instituições que ainda trabalham com a perspectiva do assistencialismo e caridade.

Para inverter esta realidade, instituições privadas e públicas oferecem apoio aos imigrantes, em especial aos refugiados, para que eles possam conhecer um pouco mais dos direitos que lhes são dados pelo ordenamento jurídico nacional.

É o caso da Cáritas Arquidiocesana de São Paulo e do Rio de Janeiro, que promovem ações para que àqueles que adentram em nosso país possam ter acesso a documentos de identificação pessoal, acesso ao Sistema Único de Saúde, à Carteira de Trabalho e Previdência Social, assim como aulas de português e dicas de acesso à justiça brasileira.

A primeira instituição trabalha conjuntamente com a Secretaria de Justiça e da Defesa da Cidadania do Estado de São Paulo e o Acnur, e dirige o Centro de Acolhida para Refugiados (CAR). O lugar é buscado pelos solicitantes de refúgio e por refugiados que chegam à capital paulista. Alguns projetos da CASP são realizados em parceria com instituições da sociedade civil, entre elas, o Senac, responsável pelo curso de língua portuguesa para refugiados, e o SESC.

Também, é o que o Centro de Defesa de Direitos Humanos e o Instituto Migrações e Direitos Humanos (IMDH), dispõem: oferecem cursos de português àqueles que chegam ao Brasil, assim como assistência jurídica e apoio social para que solicitem documentos e legalizem suas entradas.

Essas instituições garantem aos imigrantes à liberdade de deslocamento e acesso a justiça, que é um direito universal.

\section{DA ENTRADA DE ESTRANGEIROS NO BRASIL: 2011 A 2016}

Em matéria para o G1, Clara Velasco e Flávia Mantovani (2016) apontam, considerando dados dispostos pela Polícia Federal, que em 10 
anos, número de imigrantes aumentou $160 \%$ no Brasil. Só em 2015, quase 120 mil estrangeiros deram entrada no país. Haitianos lideram o ranking atual, seguidos pelos bolivianos.

O número de imigrantes registrados pela Polícia Federal aumentou $160 \%$ em dez anos. Segundo dados da PF, 117.745 estrangeiros deram entrada no país em 2015 - um aumento de 2,6 vezes em relação a 2006 (VELASCO e MANTOVANI, 2016).

Em 2015, os haitianos lideraram o ranking de chegada ao país pelo segundo ano consecutivo, de acordo com os dados da Polícia Federal. Foram 14.535 haitianos registrados (BRASIL 2017). A nacionalidade é a que mais se destaca pelo crescimento nos últimos cinco anos. Em 2011, segundo a PF, apenas 481 haitianos deram entrada no país - ou seja, houve um aumento de mais de 30 vezes.

Os bolivianos também mantiveram a posição de 2014 para 2015: o segundo lugar. Foram 8.407 registros no país no ano passado, o que representa uma queda de $32 \%$ em relação aos dados de 2011 , quando 12.465 bolivianos entraram no Brasil. Em 2015, eles são seguidos pelos colombianos (7.653), argentinos (6.147), chineses (5.798), portugueses (4.861) paraguaios (4.841) e norte-americanos (4.747) (VELASCO e MANTOVANI, 2016).

No caso dos refugiados especificamente, o número total no país aumentou 12\% em 2016, informa o relatório sobre refúgio no Brasil do Comitê Nacional para os Refugiados (CONARE), do Ministério da Justiça e Segurança Pública.

Até o final do ano passado, foram reconhecidos 9.552 refugiados de 82 nacionalidades. Desses, 8.522 foram reconhecidos por vias tradicionais de elegibilidade, 713 chegaram ao Brasil por meio de reassentamento e a 317 foram estendidos os efeitos da condição de refugiado de algum familiar (BRASIL, 2017).

Os refugiados reconhecidos em 2016 são em maior parte da Síria (326), República Democrática do Congo (189), Paquistão (98), Palestina (57) e Angola (26) (BRASIL, 2017).

Já os pedidos de refúgio caíram $64 \%$ em 2016, em comparação com 2015, sobretudo em decorrência da diminuição das solicitações de nacionais haitianos. Segundo dados apresentados pelo Ministério da Justiça e Segurança Pública, os países com maior número de solicitantes de refúgio no Brasil em 2016 foram Venezuela (3.375), Cuba (1.370), Angola (1.353), Haiti (646) e Síria (391) (BRASIL, 2017). 
De acordo com o relatório do Ministério da Justiça e Segurança Pública (2017), apenas no ano passado, 3.375 venezuelanos solicitaram refúgio no Brasil, cerca de $33 \%$ das solicitações registradas no País. Em 2015 foram contabilizados 829 pedidos de refúgio de nacionais venezuelanos.

Em 2017, o Conselho Nacional de Imigração (CNIg) aprovou a Resolução Normativa $\mathrm{n}^{\circ} 126$, de $2 / 3 / 2017$, que trata da concessão de residência temporária a cidadão de país fronteiriço, com o objetivo de estabelecer políticas migratórias que garantam o respeito integral aos direitos humanos dos migrantes e seu pleno acesso à justiça, à educação e à saúde.

Porém, para Wagner Oliveira, pesquisador da FGV, para a revista Nexo Jornal LTDA (2017), o Brasil já foi, no passado, um país com uma parcela muito importante de migrantes em sua população. Mas hoje essa proporção é baixa, são cerca de 700 mil estrangeiros numa população de mais de 200 milhões.

Como critério de comparação, a média de países em desenvolvimento, que é mais baixa que a média mundial, é de 1,7\%, isso já levando em conta que países como a Índia, com mais de 05 milhões de imigrantes no seu território, também apresentam baixo percentual dado o tamanho de sua população (CHARLEAUX, 2017).

Tem, também, os Estados Unidos, país com maior volume absoluto de migrantes na sua população, com 14,6\%, e países conhecidos por políticas ativas de atração de migrantes como o Canadá e a Austrália, com respectivamente 21,8\% e 28,4\% (CHARLEAUX, 2017).

Por outro lado, o Brasil é o país com maior número de refugiados sírios na América Latina, ainda que numericamente sejam pouco representativos (cerca de 3.000).

Os dados apresentados com fidedignidade são referentes, em sua maioria, ao ano de 2016 e anteriores. Infelizmente não foi encontrado dados referentes ao ano de 2017, 2018 e 2019 durante o levantamento da pesquisa.

Esses imigrantes adentram no país de várias formas, sendo elas legais ou não. Algumas pessoas, às vezes acompanhadas de suas famílias, passam a barreira territorial brasileira andando, em transportes terrestres clandestinos precários, em carros disponibilizados por pessoas conhecidas, pelo mar em embarcações demasiadamente arcaicas, ou mesmo pelo aeroporto ou fronteira marítima legal. Os meios são vários, e a entrada 
ocorre em várias partes do Brasil, seja pela fronteira dos países latinos americanos vizinhos, seja pela costa marítima ou mesmo zona aérea.

Para quem chega ao Brasil pelo aeroporto de Guarulhos, em São Paulo, o anseio começa em uma sala conhecida como Conector, alocada na área de desembarque. É lá onde os refugiados ficam enquanto aguardam a permissão para entrar no país. Muitos chegam sem qualquer documento. Muitas pessoas decidem tomar o Brasil como lar, pois aqui os refugiados não precisam de documentação prévia.

Devido à realidade cruel em que os refugiados viviam em seus países de origem, muitos chegam aqui apenas com a roupa do corpo, sem qualquer identificação pessoal, bens ou mesmo um lugar para ficarem. Por esta realidade, organizações não governamentais e instituições recebem estas pessoas, oferecendo a elas a oportunidade de retirarem seus documentos pessoais e legalizarem sua estadia no país tupiniquim.

\section{DO ACESSO À JUSTIÇA AOS REFUGIADOS}

Para solicitar refúgio no Brasil, aquele que se considera vítima de perseguição em seu país de origem e busca o Brasil para melhores condições de vida, deve procurar, a qualquer momento após a sua chegada ao território nacional, qualquer Delegacia da Polícia Federal ou autoridade migratória na fronteira e solicitar formalmente a proteção do governo brasileiro.

O pedido será encaminhado pela Polícia Federal e posteriormente ao CONARE, que o analisará e decidirá pelo reconhecimento ou não do refúgio. O solicitante receberá um protocolo com validade para 180 (cento e oitenta) dias e que poderá ser renovado (COLATUSSO, 2014).

Ainda, para Márcia Valdecy Andrade Da Cruz (2014), segundo o CONARE, para assegurar que os pedidos protocolados tenham fundamento, o órgão faz pesquisa por meio de imprensa e da internet, além de consultar organizações internacionais, como a ONU, e em algumas universidades com as quais mantém convênio. Essas instituições enviam relatórios ao comitê brasileiro o resultado sobre suas pesquisas que embasem o processo. Uma vez concedido o refúgio, os direitos se estendem a cônjuges, filhos, pais e outros integrantes da família que dependam economicamente do refugiado. 
A partir do momento em que o refugiado solicita o status dessa condição, automaticamente o Estado lhe garante alguns direitos básicos referentes à dignidade e os direitos humanos. No CONARE estão elencados alguns desses direitos, referentes aos direitos dos solicitantes provisórios e dos permanentes:

\begin{abstract}
- Ter acesso ao procedimento legal de solicitação de refúgio, gratuitamente e sem necessidade de advogado; Não ser devolvido para seu país de origem ou para onde sua vida possa estar em risco; - Não ser discriminado pelas autoridades governamentais e pela sociedade; - Não ser punido por entrada irregular no país; - Receber a documentação provisória assegurada pela legislação: Protocolo Provisório, Cadastro de Pessoa Física (CPF) e Carteira de Trabalho; - Ter os mesmos direitos e a mesma assistência básica de qualquer outro estrangeiro que resida legalmente no país. Entre os direitos civis básicos estão a liberdade de pensamento, de deslocamento e de não ser submetido à tortura e a tratamentos cruéis e degradantes. Já entre os direitos econômicos, sociais e culturais estão o acesso aos serviços de saúde pública e educação, direito ao trabalho e à liberdade de culto. (ACNUR, CARTILHA DIREITOS E DEVERES DOS SOLICITANTES DE REFÚGIO NO BRASIL, 2010, P. 10)
\end{abstract}

Ainda, a legislação brasileira assegura aos refugiados, na condição de residentes, direitos que visam a sua segurança e estabilidade, entre eles, destacam-se:
- Solicitar, por meio da reunião familiar, a extensão da condição de refugiado para parentes (cônjuges, ascendentes e descendentes) e demais componentes do grupo familiar que se encontrem no território nacional, conforme estabelece a Lei 9.474 e a Resolução Normativa n. 4 do CONARE; - Receber toda a documentação assegurada pela legislação: Registro Nacional de Estrangeiros (RNE), Cadastro de Pessoa Física (CPF), Carteira de Trabalho e passaporte para estrangeiro - no caso de viagens previamente autorizadas pelo CONARE; - Requerer a permanência após ter vivido quatro anos no país na condição de refugiado; - Solicitar a permanência no Brasil em razão de ter cônjuge ou filho brasileiro; - Reivindicar o acesso a procedimentos facilitados para o reconhecimento de certificados e diplomas. (ACNUR, CARTILHA DIREITOS E DEVERES DOS SOLICITANTES DE REFÚGIO NO BRASIL, 2010, P. 10)

Contudo, a legislação brasileira é clara também quanto aos deveres dos refugiados e/ou dos que aguardam decisão governamental, quais sejam: 


\begin{abstract}
- Respeitar a Constituição Federal e as leis brasileiras, como todos os brasileiros e estrangeiros residentes no país. Qualquer crime ou infração cometida terá o mesmo tratamento legal dado aos cidadãos brasileiros; - Observar especialmente as leis específicas de proteção das crianças, dos adolescentes e da mulher; - Não exercer atividades de natureza política, nos termos do artigo 107 da Lei 6.815/80; - Informar a Polícia Federal e o CONARE, no prazo de 30 dias, qualquer mudança de endereço; - Manter sua documentação atualizada. (ACNUR, CARTILHA DIREITOS E DEVERES DOS SOLICITANTES DE REFÚGIO NO BRASIL, 2010, P. 11)
\end{abstract}

Sendo assim, o refugiado tem direitos básicos garantidos a fim de que sua dignidade e outras garantias fundamentais sejam cumpridas. Contudo, deve cumprir com alguns deveres a fim de efetivar o Estado Democrático de Direito.

\title{
6 CONSIDERAÇÕES FINAIS
}

$\mathrm{O}$ art. $5^{\circ}$ da Constituição Federal garante que todos são iguais perante a lei, sem distinção de qualquer natureza, garantindo-se aos brasileiros e aos estrangeiros residentes no país a inviolabilidade do direito a vida, à liberdade, à igualdade, à segurança e à propriedade.

Nesta máxima, a entrada de estrangeiros em território nacional vem crescendo consideravelmente. Esses imigrantes buscam no Brasil melhores condições de vida e efetividade em direitos básicos.

Os países que se destacaram no envio de imigrantes nos últimos anos foram Bangladesh, Senegal e Angola. Porém, a expansão das imigrações atuais no Brasil vem acompanhada por várias problemáticas, como, por exemplo, o aumento da xenofobia - sobretudo para com as populações advindas de países subdesenvolvidos.

Esses imigrantes, quando adentram no país, frequentemente sofrem com as precárias condições de vida, uma vez que muitos chegam aqui sem emprego, moradia, dinheiro e demasiadamente passam fome e necessidade de itens básicos a higiene e saúde. Há também a falta de comunicação, pois a grande maioria chega ao Brasil sem ao menos entender a língua pátria, o que dificulta muito a adaptação do imigrante aqui.

Ainda, é corriqueiro os casos de trabalhos análogos ao escravo praticados no país, sobretudo com migrantes haitianos, na região Norte. 
Também, o aumento do tráfico de pessoas coloca o Brasil no alvo de imigrantes ilegais.

Para garantir maior efetivação na qualidade de vida e os direitos a essas pessoas que chegam ao Brasil à procura de melhores condições de vida, foi aprovado no Congresso Nacional o Projeto de Lei que institui uma nova Lei de Migração para o Brasil, em substituição ao defasado Estatuto do Estrangeiro (Lei 6.815/1980), forjado ainda no período da ditadura militar.

A Lei 13.445/17 prevê expressamente princípios e garantias, em consonância com as diretrizes de proteção internacional de direitos humanos, que podem servir para nortear políticas públicas e decisões judiciais em favor da proteção dos direitos humanos dos migrantes.

A proposta da nova Lei de Migração brasileira, que já representa grande avanço na proteção de direitos humanos em relação ao Estatuto do Estrangeiro antes vigente, ainda pode ser aprimorada a partir do debate democrático no Poder Legislativo, evitando contradições e até mesmo alguns pontos de retrocesso.

É importante ressaltar, também, o Estatuto do Refugiado, materializado pela Lei 9.474 de 1997, uma vez que essa classe de imigrante vem tomando grande destaque nas estatísticas de entrada em território tupiniquim. Os refugiados buscam fugir das perseguições políticas e ideológicas, do preconceito, da intolerância, muitas vezes de guerras e conflitos que ameaçam suas garantias fundamentais, como a própria vida.

Para isto, políticas públicas voltadas à assistência e integração dos refugiados são imprescindíveis para assegurar-lhes os direitos econômicos, sociais e culturais, em especial o direito ao trabalho, à saúde e à educação.

Contudo, nem sempre a demanda cabe ao que é ofertado, principalmente quando a iniciativa é governamental, ficando frequentemente refugiados a mercê do trabalho de ONGs e grupos de apoio. Principalmente no que tange ao reconhecimento de direitos pelos refugiados (e também imigrantes em geral), instituições privadas e outras públicas oferecem grande apoio.

Assim, torna-se impreterível que o Estado Brasileiro, em consonância com a legislação vigente e com os princípios de direitos humanos fundamentais desenvolva e aprimore, através de políticas públicas, métodos para a recepção dos estrangeiros no território nacional, com o fim de assegura-lhes direitos básicos para garantir a dignidade. A 
nova Lei que tutela o estrangeiro foi um grande passo dado para isto, contudo, ainda há um longo caminho a ser percorrido a fim de garantir ao estrangeiro melhor qualidade de vida.

\section{REFERÊNCIASBIBLIOGRÁFICAS}

BANDEIRA, Luíza. Sem programa específico para refugiados, Brasil põe centenas de sírios no Bolsa Família. BBC Brasil, 2015. Disponível em:

http://www.bbc.com/portuguese/noticias/2015/10/151013_bolsa_familia_sirios_lab. Acesso em: 13.Dez.2018

BARRETO, Luis Paulo Teles Ferreira. O Refúgio e o CONARE. In: Refúgio, Migrações e Cidadania, Caderno de Debates 1, ACNUR e IMDH, Brasília, 2006, p. 47.

BATISTA, Vanessa Oliveira. O fluxo migratório mundial e o paradigma contemporâneo de segurança migratória. Versus, v.3, p.68 - 78, 2009.

; PARREIRA, Carolina Genovez. Perspectivas jurídicas da política migratória no Brasil. 2011. Disponível em: http://www.publicadireito.com.br/artigos/?cod=c559da2ba967eb82. Acesso em: 10.Out.2018

BRASIL. Plano de Ação do México "Para Fortalecer a Proteção Internacional dos Refugiados na América Latina". In: ACNUR - CPIDH - IMDH. Lei 9474/97 e Coletânea de Instrumentos de Proteção Internacional dos Refugiados. Brasília, ACNUR, 2004, p. 104.

2011.

. Constituição (1988). Constituição da República Federativa do Brasil. Brasília, DF, Senado,

. Lei 6.815 (1980). Estatuto do Estrangeiro. Brasília. DF, Senado, 2011.

. Secretaria Nacional de Justiça e Segurança Pública. Refúgio em Números. Brasília. DF, 2017.

Câmara Legislativa. Projeto de Lei n ${ }^{\circ}$ 5.655/2009. Brasilia. DF. 2011

. Refugiados, Justiça, Governo Federal. 2014. Disponível em: http://www.justica.gov.br/seusdireitos/estrangeiros/refugio. Acesso em: 09.out.2018.

CHARLEAUX, João Paulo. Qual o retrato da migração estrangeira hoje no Brasil, segundo este especialista: Wagner Oliveira, da FGV, fala ao 'Nexo' sobre o perfil dos estrangeiros que vivem no país e sobre mitos como o de que eles 'roubam o trabalho' de brasileiros. Nexo Jornal LTDA. 2017. Disponível em: https://www.nexojornal.com.br/entrevista/2017/08/26/Qual-o-retrato-damigra\%C3\%A7\% $3 \%$ A3o-estrangeira-hoje-no-Brasil-segundo-este-especialista. Acesso em: 13.dez.2018. 
DIREITO DOS IMIGRANTES AO SISTEMA PÚBLICO DE SAÚDE. Revista online O

Estrangeiro. 2013. Disponível em: https://oestrangeiro.org/2013/03/29/direito-dos-imigrantes-aosistema-publico-de-saude/. Acesso em: 13. dez.2018.

FERREIRA, Aurélio Buarque de Holanda. Dicionário Aurélio Básico da Língua Portuguesa. Rio de Janeiro: Nova Fronteira, 1988.

LENZA, Pedro. Direito Constitucional Esquematizado. 16. ed. São Paulo: Saraiva, 2012.

PIOVESANA, Flávia. Declaração Universal dos Direitos Humanos. 1948.

MARINUCCI, Roberto. MILESI, Rosita. Migrações Internacionais: em busca da cidadania universal. In: Sociedade em Debate. Vol. 11. N. 1 e 2. Pelotas: Universidade Católica de Pelotas; EDUCAT, 2005, p.32.

MILES, Rosita; CARLET, Flávia. Refugiados e Políticas Públicas: pela solidariedade, contra a exploração. Instituto de Migração e Direito Humanos. 2006. Disponível em:

http://www.migrante.org.br/index.php/refugiados-as2/154-refugiados-e-politicas-publicas-pelasolidariedade-contra-a-exploracao. Acesso: 13.dez.2018.

ORGANIZAÇÃO DAS NAÇÕES UNIDAS (ONU). Direitos Humanos e o Direito Constitucional Internacional. 14 ed. Saraiva, 2013.

SÃO PAULO. Coordenação de Políticas para Migrantes. 2015. Disponível em:

http://www.prefeitura.sp.gov.br/cidade/secretarias/direitos_humanos/migrantes/crai/index.php.

Acesso em: 09.out.2018.

VELASCO, Clara; MANTOVANI, Flávia. Em 10 anos, número de imigrantes aumenta $160 \%$ no Brasil, diz PF. São Paulo: São Paulo, 2016. Disponível em:

http://g1.globo.com/mundo/noticia/2016/06/em-10-anos-numero-de-imigrantes-aumenta-160-nobrasil-diz-pf.html. Acesso em: 12.dez.2018. 